\title{
Stress Related Factors Among Nurses Working in Accident and Emergency in a Selected Federal Government Hospital in South-South Nigeria
}

\author{
Duke Emon Umoe ${ }^{1}$, Regina Ella E. ${ }^{1}$, Ekpoanwan Esienumoh ${ }^{1}$, \\ Ndukaku Nwakwue C. ${ }^{1} \&$ Tam-Princewill Catherine ${ }^{2}$ \\ ${ }^{1}$ Department of Nursing Science, University of Calabar, Calabar, Nigeria \\ ${ }^{2}$ University of Port Harcourt Teaching Hospital, Nigeria \\ Correspondence: Duke Emon Umoe, Department of Nursing Science, University of Calabar, Calabar, Nigeria. \\ E-mail: emonduke2005@yahoo.com
}

Received: December 9, 2019 Accepted: May 11, 2020 Online Published: June 16, 2020

doi:10.5539/gjhs.v12n8p166

URL: https://doi.org/10.5539/gjhs.v12n8p166

\begin{abstract}
Stress bears a negative effect on nurses' lives and work which includes relationships, such as family life and social relationship. This is because nurses spend more time by the patients and in the healthcare setting than any other healthcare professional. This study examined the stress related factors among nurses working in Accident and Emergency (A\&E) Department of one the federal hospitals in South-south Nigeria. The study had four (4) specific objectives and four (4) hypotheses. The study adopted a descriptive research design. Convenient sampling technique was used to recruit fifty-seven (57) nurses who are currently working or have worked in the A\&E unit of the hospital. Data collection was with structured questionnaire aided by two research assistants. Permission was obtained from the ethics committee of the hospital. Findings revealed that $49(86 \%)$ do not observe break during their shift and a further $50(88 \%)$ go home completely exhausted. $54(95 \%)$ of the respondents viewed that the workload in A \& E is enormous. Staff shortage accounted for 56 (98.5\%) of stressors. 47 (83\%) of the perception of stressors from respondents are due to problems in interaction with the administration. The study identified various coping mechanisms nurses adopt to combat stressful shifts. Findings reveals that friends 49 (86\%), work associates 54 (92.5\%), faith $55(96.5 / \%)$ and personal time alone 56 (98.5\%) were sources of coping with the stress. The test of hypothesis showed that positive calculated $r$-value is greater than the critical r-value of 0.269 at 0.05 alpha level with 55 degree of freedom. Thus, there is a significant relationship between stress-related factors and stress among nurses. Conclusion was based on the findings of this study which was recommended amongst others that hospitals should provide a counsellor through employee assistance programs to help nurses during burnout.
\end{abstract}

Keywords: nurses, stress, accident and emergency, burnout, healthcare professional, coping mechanism

\section{Introduction}

Nursing remains one of the most stressful professions in the healthcare setting. Globally, stress in nursing has been analysed and identified as a health burden for nurses. Previous surveys have demonstrated that stress-linked factors in nursing results in anxiety, depression, insomnia (Wong et al., 2001); increased cardiovascular risk (European Foundation for the Improvement of Living and Working Conditions, 2007); weakened immune system and lessen immunity to illnesses (Health and Safety Executive, 2012). Furthermore, stress bears a negative effect on nurses' lives and work which includes relationships, such as family life and social relationship (Duke et al., 2015a). Stress has so affected nurses that divorce rate among nurses ranks the highest amongst other healthcare workers. According to the European Foundation for the Improvement of Living and Working Conditions (2011), the effect of job related stress includes absenteeism from work, early retirement, low productivity, poor quality of care delivered. This will reduce patient satisfaction as well as impede the length of stay in the hospital (Duke et al., 2015b). Furthermore, studies suggest that nurses often suffer from high levels of work-related stress, jeopardizing nurses' health and patients' lives, undermining quality of services and increasing the cost of healthcare (Spânu, 2013; Dhaka, 2014; Einstein, 2014; Mulcahy, 2014; Salilih, 2014; Dal Santo, 2016; Christodoulou-Fella, 2017; Jones, 2017). Therefore this study's objectives are:

- to determine the presence of stressors in the Accident and Emergency (A\&E) Department of one the 
federal hospitals in South-south Nigeria.

- to ascertain the occupational stress relating to the hospital organization of one the Federal hospitals in South-south Nigeria

- to identify the types of stressors among nurses working in Accident and Emergency Department of one the Federal hospitals in South-south Nigeria

- to examine how nurses in Accident and Emergency Department of one the Federal hospitals in South-south Nigeria cope with stress.

\section{Methodology}

The research design for this study was a descriptive design (Creswell et al., 2017). The rationale for the choice of research design is that descriptive research is often used as a pre-cursor to more quantitative research designs with the general overview giving some valuable pointers as to what variables are worth testing quantitatively. The study was carried out in the Accident and Emergency Department of a federal government owned hospital in South-South Nigeria. The department is a 22-beded facility which offers services to an average of 120 patients weekly. Some cases were managed and discharged home by the Accident and Emergency Department nurses and doctors within 48 hours while others are admitted, resuscitated and referred to the various specialist teams on call for admission into the various specialty wards. In this study, the research population were nurses. There were three hundred and thirty (330) nurses in the hospital. The target population were nurses who specialised in Accident and Emergency Department. Also, nurses who had worked there were also included in the study. There were sixty-six (66) nurses involved in the study. The sampling technique used for this study was convenience sampling since the population was small. This techniques was adopted because every member of the research population stood a chance to be selected. In practice, the sample size used in this study was determined based on the number of nurses working in the Accident and Emergency Department of UPTH. Preliminary enquiry about the nurses' staff strength working in the Accident and Emergency Department of UPTH was 66 who were currently working in A\&E or had worked there over the past 5 years. To determine the sample size, Taro and Yamane was used. The Taro Yamane method of sample size formula is stated thus:

$n=N\left(1+N e^{2}\right)$. Where $\mathrm{n}=$ corrected sample size, $\mathrm{N}=$ population size, and $\mathrm{e}=$ Margin of error $(\mathrm{MoE}), \mathrm{e}=0.05$ based on the research condition.

The sample size after calculation is 57 . Two research assistants administered the questionnaires to nurses and same collected for analysis. A structured questionnaire was used in this study to elicit information from the respondents. The method of data analysis was by the percentages and the use of Pearson product moment correlation for hypothesis by an independent analyst.

\subsection{Reliability of Instrument}

For this study, Test-retest method was used. The Test-retest was used measures the correlation between scores from one administration of an instrument to another, usually within an interval of 2 to 3 weeks. Unlike pre-post-tests, no treatment occurs between the first and second administrations of the instrument, to test-retest reliability (LoBiondo-Wood \& Haber, 2014).

\subsection{Ethical Consideration}

The researchers adhered to maintaining good ethical conduct in the course of conducting this study. Firstly, a letter of introduction was obtained from the Head of Department, Department of Nursing Science University of Calabar. Secondly, ethical clearance was obtained from the ethical Committee of the hospital. Thirdly, consent was sought from the respondents before questionnaires were administered to them by the researcher and two assistants. Upon completion of the questionnaire, same was collected for analysis. By so doing, the principles of anonymity and confidentiality was maintained as the respondents were instructed not to use any word/name that would identify their person. Participation was free.

\section{Results}

\subsection{Demographic Characteristics of Respondents}

A total of 57 questionnaire were administered and collected by two research assistants. All questionnaires were returned completed. Table 1 shows the characteristics of the respondents. 
Table 1. The Demographic Characteristics of the Participants $(n=57)$

\begin{tabular}{|c|c|c|c|c|}
\hline $\mathrm{S} / \mathrm{NO}$ & ITEM & CLASS & FREQUENCY & PERCENTAGE (\%) \\
\hline \multirow{5}{*}{1} & \multirow{5}{*}{ Age } & $16-25$ & 12 & 21 \\
\hline & & $26-35$ & 21 & 37 \\
\hline & & $36-45$ & 18 & 31.5 \\
\hline & & $46 \&$ above & 6 & 10.5 \\
\hline & & Total & 57 & 100 \\
\hline \multirow{8}{*}{2} & \multirow{8}{*}{ Rank } & NO II & 18 & 31.5 \\
\hline & & NO I & 11 & 19.5 \\
\hline & & SNO & 9 & 16.5 \\
\hline & & PNO & 7 & 12 \\
\hline & & $\mathrm{ACNO}$ & 7 & 12 \\
\hline & & $\mathrm{CNO}$ & 4 & 7 \\
\hline & & ADNS & 1 & 1.5 \\
\hline & & Total & 57 & 100 \\
\hline \multirow{6}{*}{3} & \multirow{6}{*}{ Marital status } & Single & 22 & 39 \\
\hline & & Married & 25 & 44 \\
\hline & & Divorced & 2 & 3.5 \\
\hline & & Separated & 3 & 5 \\
\hline & & Widowed & 5 & 8.5 \\
\hline & & Total & 57 & 100 \\
\hline \multirow{6}{*}{4} & \multirow{6}{*}{ Years of experience } & $1-5$ & 19 & 33 \\
\hline & & $6-10$ & 24 & 42 \\
\hline & & $11-15$ & 9 & 16.5 \\
\hline & & $16-20$ & 3 & 5 \\
\hline & & 21 and above & 2 & 3.5 \\
\hline & & Total & 57 & 100 \\
\hline \multirow{4}{*}{5} & \multirow{4}{*}{ Religion } & Christain & 55 & 96.5 \\
\hline & & Islam & 2 & 3.5 \\
\hline & & African Religion & 0 & 0 \\
\hline & & Total & 57 & 100 \\
\hline \multirow{3}{*}{6} & \multirow{3}{*}{ Gender } & Male & 18 & 32 \\
\hline & & Female & 39 & 68 \\
\hline & & Total & 57 & 100 \\
\hline
\end{tabular}

\section{To determine the presence of stressors in the Accident and Emergency Department}

To meet this objective, five (5) questions (7-12) were asked. Table 2 describes the responses. Results on table 2 above showed that nurse-patient ratio per shift is adequate. Responses were close as $29(51 \%)$ answered yes while $28(49 \%)$ answered No. The result also showed that A\&E department was the only acute unit around the area as 48 (84\%) opined Yes while $9(16 \%)$ opined No. 45 (79\%) opined Yes to the question on the number of patient turnout as being much while $12(21 \%)$ answered No. On the question: if the number of junior nurses per shift is less hence much task is assigned to them? Responses showed that 41 (72\%) opined Yes while $16(28 \%)$ opined No. question 11 enquired from the respondents if sometimes they do not observe a break. Response were $49(86 \%)$ and $8(14 \%)$ for Yes and No respectively. Last question in this objective (question 12) asked respondents if they always go home 
completely exhausted. 50 (88\%) opined Yes while 7 (12\%) opined No.

Table 2. The Presence of Stressors in the Accident and Emergency Department ( $\mathrm{n}=57)$

\begin{tabular}{|c|c|c|c|c|c|}
\hline \multirow{2}{*}{$\mathrm{S} / \mathrm{NO}$} & \multirow{2}{*}{ QUESTION } & \multicolumn{4}{|c|}{ RESPONSE } \\
\hline & & YES & $\%$ & NO & $\%$ \\
\hline 7 & The number of nurse- patient ratio per shift is adequate & 29 & 51 & 28 & 49 \\
\hline 8 & $\begin{array}{l}\text { The Accident and Emergency Department of University of Port Harcourt } \\
\text { Teaching Hospital is the only acute unit around the area }\end{array}$ & 48 & 84 & 9 & 16 \\
\hline 9 & The number of patient turnout is much & 45 & 79 & 12 & 21 \\
\hline 10 & The number of junior nurses is less hence much task is assigned to them & 41 & 72 & 16 & 28 \\
\hline 11 & Sometimes I do not observe break in a shift. & 49 & 86 & 8 & 14 \\
\hline 12 & I always go home completely exhausted & 50 & 88 & 7 & 12 \\
\hline
\end{tabular}

To examine the types of stressors among nurses working in Accident and Emergency Department.

To meet this objectives, 5 questions (13-17) were asked. Table 3 shows the types of stressors among nurses working in Accident and Emergency.

The result on Table 3 above showed that 32 (74\%) strongly agreed; workload in the A \& E was much while 12 $(21 \%)$ while $3(3 \%)$ strongly disagreed. On the role of ambiguity within the department, responses showed that 21 (37\%) strongly agreed, 34 (59.5\%) agreed, while $3(3.5 \%)$ strongly disagreed. Result on whether staff shortage increased stress in the department showed that $35(62 \%)$ strongly agreed, $21(36.5 \%)$ agreed while $1(1.5 \%)$ strongly disagreed. $30(53 \%)$ strongly agreed, $12(21 \%)$ agreed that colleagues were not doing their job and there were poorly motivated at work 9 (15.5\%) strongly disagreed, 4 (7\%) disagreed while $2(3.5 \%)$ had no idea. Lastly in this section: 35 (62\%) strongly agreed, 19 (33\%) agreed when asked if inadequate remuneration for work done and the economic crisis in a country was great while $3(5 \%)$ strongly disagreed.

Table 3. Types of Stressors among Nurses Working in Accident and Emergency Department $(n=57)$

\begin{tabular}{|c|c|c|c|c|c|c|c|c|c|c|c|}
\hline \multirow[t]{2}{*}{$\mathrm{S} / \mathrm{NO}$} & \multirow[t]{2}{*}{ Questions } & \multicolumn{2}{|c|}{$\begin{array}{l}\text { Strongly } \\
\text { agreed }\end{array}$} & \multicolumn{2}{|c|}{ Agreed } & \multicolumn{2}{|c|}{$\begin{array}{l}\text { Strongly } \\
\text { disagreed }\end{array}$} & \multicolumn{2}{|c|}{ Disagreed } & \multicolumn{2}{|c|}{$\begin{array}{l}\text { Don’t } \\
\text { know }\end{array}$} \\
\hline & & $\mathrm{n}$ & $\%$ & $\mathrm{n}$ & $\%$ & $\mathrm{n}$ & $\%$ & $\mathrm{n}$ & $\%$ & $\mathrm{n}$ & $\%$ \\
\hline 13 & The workload in A \& E is too much & 32 & 74 & 12 & 21 & 3 & 5 & 0 & 0 & 0 & 0 \\
\hline 14 & $\begin{array}{l}\text { There is role ambiguity within the } \\
\text { department }\end{array}$ & 21 & 37 & 34 & 59.5 & 2 & 3.5 & 0 & 0 & 0 & 0 \\
\hline 15 & $\begin{array}{l}\text { Staff shortage increases stress in the } \\
\text { department }\end{array}$ & 35 & 62 & 21 & 36.5 & 1 & 1.5 & 0 & 0 & 0 & 0 \\
\hline 16 & $\begin{array}{l}\text { Fellow workers are not doing their jobs and } \\
\text { there are poorly motivated co-workers }\end{array}$ & 30 & 53 & 12 & 21 & 9 & 15.5 & 4 & 7 & 2 & 3.5 \\
\hline 17 & $\begin{array}{l}\text { Inadequate remuneration for work done and } \\
\text { the economic crisis in a country is great. }\end{array}$ & 35 & 62 & 19 & 33 & 3 & 5 & 0 & 0 & 0 & 0 \\
\hline
\end{tabular}

\section{To ascertain the occupational stress relating from the hospital organisation}

To achieve this objective, 5 questions were asked (questions 18-22). Responses were displayed in Table 4 below. From the table, question 18 asked about problems with interacting with the administration had an influence on my perception of stress. 29 (51\%) strongly agreed, 18 (32\%) agreed, 7 (12\%) strongly disagreed, while 3 (5\%) respondents disagreed. Question 19 enquired if barriers in interacting with colleagues influenced my perception of stress. Statistical analysis showed that 20 (35\%) strongly agreed, $15(26 \%)$ agreed, $11(19 \%)$ strongly disagreed, 6 (10\%) disagreed, while $5(9 \%)$ had no idea. Question 20 was based on whether conflicts amongst colleagues influenced my perception of stress. Responses showed that 21 (37\%) strongly agreed, 27 (47\%) agreed, 7 (12\%) 
strongly disagreed, while $2(3.5 \%)$ disagreed. Question 21 dwelt on demands from clients/patients and health risks posed by contact with patients influence my perception of stress. Responses from respondents were as follows: 26 (45\%) strongly agreed, 18 (32\%) agreed, $10(18 \%)$ strongly disagreed while $3(5 \%)$ disagreed. Lastly, question 22 assessed if tight shifting pattern without adequate off days influenced my perception of stress. 34 (60\%) strongly agreed, 12 (21\%) agreed, 8 (14\%) strongly disagreed while 3 (5\%) disagreed.

Table 4. Occupational Stress relating from the Hospital Organisation ( $\mathrm{n}=57)$

\begin{tabular}{|c|c|c|c|c|c|c|c|c|c|}
\hline \multirow[t]{2}{*}{$\mathrm{S} / \mathrm{NO}$} & \multirow[t]{2}{*}{ Item } & \multicolumn{2}{|c|}{$\begin{array}{l}\text { Strongly } \\
\text { agreed }\end{array}$} & \multicolumn{2}{|c|}{ Agreed } & \multicolumn{2}{|c|}{$\begin{array}{l}\text { Strongly } \\
\text { disagreed }\end{array}$} & \multicolumn{2}{|c|}{ Disagreed } \\
\hline & & $\mathrm{n}$ & $\%$ & $\mathrm{n}$ & $\%$ & $\mathrm{n}$ & $\%$ & $\mathrm{n}$ & $\%$ \\
\hline 18 & $\begin{array}{l}\text { Problems with interacting with the administration influence } \\
\text { my perception of stress }\end{array}$ & 29 & 51 & 18 & 32 & 7 & 12 & 3 & 5 \\
\hline 19 & $\begin{array}{l}\text { Barriers in interacting with colleagues influence my } \\
\text { perception of stress }\end{array}$ & 20 & 35 & 15 & 26 & 11 & 19 & 11 & 19 \\
\hline 20 & Conflict with colleagues influences my perception of stress & 21 & 37 & 27 & 47 & 7 & 12 & 2 & 3.5 \\
\hline 21 & $\begin{array}{l}\text { Demands from clients/patients and health risks posed by } \\
\text { contact with patients influence my perception of stress }\end{array}$ & 26 & 45 & 18 & 32 & 10 & 18 & 3 & 5 \\
\hline 22 & $\begin{array}{l}\text { Tight shifting pattern without adequate off days influences } \\
\text { my perception of stress }\end{array}$ & 34 & 60 & 12 & 21 & 8 & 14 & 3 & 5 \\
\hline
\end{tabular}

\section{To examine how nurses in Accident and Emergency Department cope with stress.}

To achieve this objective, 5 questions (23-27) were asked and responses from respondents were displayed in Table 5. Question 23 assessed if friends were the key sources of support during stressful periods. 19 (33\%) strongly agreed, 26 (46\%) agreed, 4 (7\%) strongly disagreed while 8 (14\%) disagreed. Furthermore, question 24 was developed to determine if work associates were the key sources of support during stressful periods. 21 (37\%) strongly agreed, $31(54.5 \%)$ agreed, $3(5 \%)$ strongly disagreed while $2(3.5 \%)$ disagreed. Question 25 asked if faith helped them to cope with stress. Responses showed that 21 (37\%) strongly agreed, 31 (54.5\%) agreed, 3 (5\%) strongly disagreed while $2(3.5 \%)$ disagreed. Also, question 26 centered on whether the supervisor-nurse interaction took place on a daily basis and functioned not only as a problem-solving resource. Responses showed that $37(65 \%)$ strongly agreed, $12(21 \%)$ agreed, $4(7 \%)$ strongly disagreed while $4(7 \%)$ disagreed. Lastly, Question 27 assessed if personal time alone helped to cope with stress. $36(63 \%)$ strongly agreed, $14(25 \%)$ agreed, $6(10.5 \%)$ disagree while $1(1.5 \%)$ disagreed.

Table 5. Coping Strategies of Nurses in Accident and Emergency Department.(n=57)

\begin{tabular}{|c|c|c|c|c|c|c|c|c|c|c|c|}
\hline \multirow[t]{2}{*}{$\mathrm{S} / \mathrm{NO}$} & \multirow[t]{2}{*}{ Item } & \multicolumn{2}{|c|}{$\begin{array}{l}\text { Strongly } \\
\text { agreed }\end{array}$} & \multicolumn{2}{|c|}{ Agreed } & \multicolumn{2}{|c|}{$\begin{array}{l}\text { Strongly } \\
\text { disagreed }\end{array}$} & \multicolumn{2}{|c|}{ Disagreed } & \multicolumn{2}{|c|}{$\begin{array}{l}\text { Don't } \\
\text { know }\end{array}$} \\
\hline & & $\mathrm{n}$ & $\%$ & $\mathrm{n}$ & $\%$ & $\mathrm{n}$ & $\%$ & $\mathrm{n}$ & $\%$ & $\mathrm{n}$ & $\%$ \\
\hline 23 & $\begin{array}{l}\text { Friends are the key sources of support during } \\
\text { stressful periods }\end{array}$ & 19 & 33 & 26 & 46 & 4 & 7 & 8 & 14 & 0 & 0 \\
\hline 24 & $\begin{array}{l}\text { Work associates were the key sources of support } \\
\text { during stressful periods }\end{array}$ & 21 & 37 & 31 & 54.5 & 3 & 5 & 2 & 3.5 & 0 & 0 \\
\hline 25 & My faith helps me to cope with stress & 38 & 67 & 12 & 21 & 3 & 5 & 4 & 7 & 0 & 0 \\
\hline 26 & $\begin{array}{l}\text { Supervisor-nurse interaction takes place on a } \\
\text { daily basis and function not only as a } \\
\text { problem-solving resource but as a learning } \\
\text { process }\end{array}$ & 37 & 31 & 12 & 21 & 4 & 7 & 4 & 7 & 0 & 0 \\
\hline 27 & Personal time alone helps me cope with stress. & 36 & 63 & 14 & 25 & 6 & 10.5 & 1 & 1.5 & 0 & 0 \\
\hline
\end{tabular}




\subsection{Hypothesis One}

\section{$\mathbf{H}_{\mathbf{0}}=$ There is no significant relationship between stress related factors and stress among nurses.}

\section{$\mathbf{H}_{1}=$ There is a significant relationship between stress related factors and stress among nurses.}

The null form of hypothesis one stated that there is no significant relationship between stresses related factors and stress among nurses. The independent variable was stress related factors, while the dependent variable was stress among nurses. Since the two variables were measured continuously, the scores obtained from the study respondents on these variables were correlated using Pearson product moment correlation (PPMC) analysis with the aid of SPSS (Version 20). The summary of the result is presented in Table 6. From table 6, the calculated $\mathrm{r}$-value is 0.309 , and this represents the observed relationship between stress related factors and stress among nurses. This positive calculated $r$-value is greater than the critical r-value of 0.269 at 0.05 alpha level with 55 degree of freedom. With this result, the null hypothesis was rejected while the alternative hypothesis was retained. The interpretation of this result is that there is a significant relationship between stress-related factors and stress among nurses. Further implication of the significant positive calculated r-value is that the higher the stress related factors among nurses, the greater the stress among nurses.

Table 6. Summary of the result of the Pearson product moment correlation (PPMC) analysis of the relationship between stress related factors and stress among nurses $(n=57)$

\begin{tabular}{|c|c|c|c|c|c|}
\hline Variable & $\begin{array}{l}\sum \mathrm{X} \\
\sum \mathrm{Y}\end{array}$ & $\begin{array}{l}\sum \mathrm{X}^{2} \\
\sum \mathrm{Y}^{2}\end{array}$ & $\sum X Y$ & r-value & p-level \\
\hline Stress related factors & 936 & 15928 & \multirow{2}{*}{15399} & \multirow{2}{*}{.309} & \multirow{2}{*}{.019} \\
\hline Stress among nurses & 930 & 15478 & & & \\
\hline
\end{tabular}

${ }^{*} \mathrm{P}<.05 ; \mathrm{df}=55 ;$ Critical r-value $=0.261$.

\subsection{Hypothesis Two}

$\mathbf{H}_{\mathbf{0}}=$ There is no significant influence of the rank of nurses on stress among nurses.

$\mathrm{H}_{1}=$ There is a significant influence of the rank of nurses on stress among nurses.

There is no significant influence of the rank of nurses on stress among nurses. The independent variable was the rank of nurses, while the dependent variable was stress among nurses. One-way Analysis of Variance was used to test this hypothesis at .05 level of significance. The result of the analysis is presented in Table 7 . The result of the data analysis from Table 7 shows that the calculated F-value of 0.802 is less than the critical F-value of 2.29 at .05 level of significance with 6 and 50 degrees of freedom. Thus, the null hypothesis was retained, while the alternative hypothesis was rejected. This implies that there is no significant influence of the rank of nurses on stress among nurses.

Table 7. Summary of result of one-way analysis of variance of the influence of the level of nurses on stress among nurses $(\mathrm{n}=57)$

\begin{tabular}{llll}
\hline Level of Nurses & N & Mean & Std. Deviation \\
\hline & & 17.00 & 1.782 \\
NO II & 18 & 15.73 & 2.867 \\
NO I & 11 & 16.22 & 2.438 \\
SNO & 9 & 16.29 & 2.870 \\
PNO & 7 & 16.71 & 2.289 \\
ACNO & 7 & 14.50 & 2.082 \\
CNO & 4 & 16.00 &. \\
ADNS & 1 & 16.32 & 2.331 \\
Total & 57 & & \\
\hline
\end{tabular}




\begin{tabular}{llllll}
\hline Source of variation & Sum of Squares & Df & Mean Square & F & Sig. \\
\hline Between Groups & 26.721 & 6 & 4.454 & .802 & .573 \\
Within Groups & 277.595 & 50 & 5.552 & & \\
Total & 304.316 & 56 & & & \\
\hline
\end{tabular}

$*$ p>.05; df 6,50: Critical F-Value $=2.29$.

\section{Discussion}

Analysis from the findings showed that the nurse-patient ratio was inadequate as the number of patient turnout was much. As a result, $49(86 \%)$ do not observe break during their shift and a further $50(88 \%)$ go home completely exhausted. This findings is in agreement with the study by Healy and colleague (2011) which found that $51 \%$ of the Emergency Department (ED) staff experience stress at work. Also, the study supports the findings by Sharma, et al (2014) who reported that nurses had no time for rest in ICU/emergency areas, of which $42 \%$ were suffering from moderate-to-severe stress. There is huge amount of burnout among emergency nurses. The findings of this study are in consonance with that of Hooper, et al (2010) which reported that more than $80 \%$ of emergency nurses have moderate-to-high levels of burnout and $86 \%$ have high levels of fatigue. There is therefore the urgent need to identify the factors responsible for increase in burnout in the Accident and Emergency unit.

Also analysis from the findings reveals that $54(95 \%)$ of the respondents viewed that the workload in A \& E is much. A further 55 (96.5\%) opined that there is presence role ambiguity within the Unit. Staff shortage accounted for $56(98.5 \%)$ of stressors. Also, $54(95 \%)$ opined that inadequate remuneration for work done is another type of stressor. There is huge amount of stressors in the A\&E unit. The findings from this study is in line with the findings from the study of Healy and colleague (2011) which identified the stressors in A\&E as poor rostering, workload, shift work, frequency at which doctors rotate, overcrowding, traumatic events, inter-staff conflict, lack of teamwork and poor managerial skills. Also, the findings agrees with the study by Gholamzadeh et al (2011) which found that work load, anger developed during interaction with patients or their relatives, being exposed to health and safety hazards, lack of support by nursing administrators, absence of corresponding physician in the emergency room and lack of appropriate equipment(s). From the literatures, it can be observed that workload is the recurrent stressor.

The study assessed occupational stressors from hospital organisation. Findings reveal that $47(83 \%)$ of the perception of stressors from respondents are due to for problems in interaction with the administration. Problems in interaction with Colleagues was identified by $35(61 \%)$ of respondents, conflicts with colleagues $48(84 \%)$, demands from clients/patients and health risks posed by contact with patients $54(95 \%)$ and tight shift pattern without adequate off days 54 (95\%). This findings is in agreement with studies by Healy and colleague (2011); Ross-Adjie et al. (2007) and Gholamzadeh et al. (2011) which identified occupational stressors as poor rostering, workload, shift work, frequency at which doctors rotate, overcrowding, traumatic events, inter-staff conflict, lack of teamwork and poor managerial skills. Other commonly identified stressors include aggression and violence from patients, and the death or resuscitation of a young person or child, managing patients who were critically ill, sudden or traumatic death, or having to deal with major incidents (Healy \& colleague, 2011); Ross-Adjie, et al (2007) while working in Australia on EDs, ranked violence against staff as the top-most reason for stress at workplace, followed by heavy workload, inappropriate skill mix, the need to deal with simultaneous casualty incidents, death, sexual child-abuse, and caring for high-acuity patients. Gholamzadeh et al (2011) found that work load, anger developed during interaction with patients or their relatives, being exposed to health and safety hazards, lack of support by nursing administrators, absence of corresponding physician in the emergency room and lack of appropriate equipment(s).

Various coping mechanisms nurses adopt to combat stressful shifts. Findings reveals that if friends 49 (86\%), work associates $54(92.5 \%)$, faith $55(96.5 / \%)$, supervisor-nurse interaction takes place on a daily basis and functioned not only as a problem-solving resource $53(93 \%)$, and personal time alone $56(98.5 \%)$. There is no doubt A\&E nurses are on a daily basis. Findings from this study agrees with different coping strategies identified in the study by Montero-Marin and colleagues (2014). Their study identified venting of emotions, although it was also explained by a focus on solving situations and religion; lack of development was explained mainly by cognitive avoidance, but it was also explained by venting of emotions and behavioural disengagement; neglect was explained only by behavioural disengagement. In general, a progressive decrease in levels of engagement is understood to be the response adopted by workers experiencing burnout in order to cope with stress and frustration. This aspect seems to be an important factor in explaining the differences between the subtypes from a longitudinal 
perspective and could be the keystone for develop.ping new treatment interventions adjusted to the coping strategies of each case. Cognitive and behavioural therapies, such as ACT, may be useful for all burnout types, emphasising the different modules according to the degree of dedication at work.

\section{Conclusion}

Stress bears a negative effect on nurses' life and work which includes relationships, such as family life and social relationship. This study recruited 57 respondents to determine stress related among nurses working in the accident and emergency unit of the hospital. Findings revealed that nurses are stressed on daily basis and the types of stressors workload, role ambiguity, staff shortage and inadequate remuneration. The occupational stress from hospital organisation were found to include problems in interaction with the administration, problems in interaction with colleagues, conflicts with colleagues, demands from clients/patients and health risks, and tight shift pattern without adequate off days. Coping mechanism adopted by nurses includes friends, work associates, faith, supervisor-nurse interaction and personal time alone.

\subsection{Implication to Nursing Practice}

The results from the study is very daunting. This shows that the A\&E unit is a very stressful unit to work as a nurse. This means that most nurses (especially newly qualified) will want to stir clear of postings to A\&E. To derive a better understanding of stress and burnout in the workplace, solid conceptualizations are needed that bring together the various pieces of the stress puzzle. At present, research is often conducted absent a solid theoretical and conceptual base. A more comprehensive blueprint of nurse stress and burnout in the work place needs to be developed. Empirical studies could then be conducted to investigate these very complex relationships, prospectively, over time. Once work stress is examined from a more solid theoretical and conceptual basis, then intervention studies can be initiated to assess the most useful ways to mitigate work stress. Studies need to move beyond the tendency to use descriptive designs. There is sufficient evidence to believe that work stress is a factor among health care personnel. What is less well understood is the effect of stress on patient outcomes. Studies are needed to enhance the understanding of stress and burnout on patient safety. Studies are also needed to better understand stress beyond the acute care setting. In addition, because nurse administrators are responsible for creating the environment in which nursing is practiced and patient care is given, it is important to explore interventions that will reduce the stress and burnout experienced by nurse administrators. Findings from studies of this nature could have a threefold effect. By reducing the stressful nature of the A\&E nurses' work, A\&E nurses could be more satisfied in their positions. This role satisfaction, in turn, could lead to enhancing those managerial behaviours that improve the work environment for staff nurses. Finally, improved working conditions for A\&E nurse might make the role more appealing and help correct the serious dearth of individuals interested in pursuing administrative positions.

\subsection{Recommendation and Suggestion for Further Studies}

Having rigorously conducted the study, the following recommendations are hereby proffered:

- There is the need to modify the shift pattern in A\&E so as allow nurse have enough relaxation after shift so as to avoid constant burnout.

- Stress management techniques should be included in the nursing education curriculum

- Stress management techniques should be included in the mandatory continued professional development progamme module for registered nurses.

- Hospitals should provide a counsellor through employee assistance program to help nurses during burnout.

\section{Authors' Contributions}

Dr. Emon Umoh Duke- Data analysis and discussion of findings.

Regina Ella E- Data analysis and reliability test

Ekpoanwan Esienumoh- Discussion of findings

Ndukaku Nwakwue C- Review of literature and discussion of findings.

Tam-Princewill Catherine- Data collection and ethical approval

\section{Competing Interests Statement}

The authors declare that there are no competing or potential conflicts of interest. 


\section{References}

Christodoulou-Fella, M., Middleton, N., Papathanassoglou, E. D., \& Karanikola, M. N. (2017). Exploration of the Association between Nurses' Moral Distress and Secondary Traumatic Stress Syndrome: Implications for Patient Safety in Mental Health Services. BioMed research international, 2017. https://doi.org/10.1155/2017/1908712

Creswell, J. W., \& Creswell, J. D. (2017). Research design: Qualitative, quantitative, and mixed methods approaches. Sage publications.

Dal Santo, L., Pohl, S., \& Battistelli, A. (2016). The nurse-patient emotional interaction in quality of worklife: The role of empathy and emotional dissonance. Scholars' Press.

Dhaka, B. (2014). The Determinants Of Job Satisfaction Among Nurses Of Government Hospitals: A Case Study In Bangladesh (Doctoral Dissertation, University Of Science \& Technology).

Duke, E. U., Mgbekem, M. A., Nsemo, A. D., Ojong-Alacia, M. M., \& Mobolaji-Olajide, O. M. (2015a). Influence of marital status on attitude of midwives towards OSCE and their performance in the examination in Akwa Ibom and Cross River States, Nigeria. Journal of Education and Training Studies, 3(4), 119-126. https://doi.org/10.11114/jets.v3i4.812

Duke, E. U., Nsemo, A. D., Ojong-Alasia, M. M., Osuchukwu, E. C., Nkwonta, C. A., \& Mobolaji-Olajide, M. O. (2015b). Influence of Age on Perception of Midwives and Their Performance in Objective Structured Clincial Examination (Osce) in Nigeria. Journal of Education and Training Studies, 3(5), 216-224. https://doi.org/10.11114/jets.v3i5.878

Einstein, A. (2014). Stress, Mental Health, and Mental Illness 101. Workplace Mental Health Manual for Nurse Managers.

European Foundation for the Improvement of Living and Working Conditions. (2007). Fourth European Working Conditions Survey. Retrieved December 12, 2019, from https://www.eurofound.europa.eu/sites/default/files/ef_publication/field_ef_document/ef0698en.pdf

European Foundation for the Improvement of Living and Working Conditions (2011). European Foundation for the Improvement of Living and Working Conditions (Eurofound). Retrieved December 12, 2019, from https://www.eurofound.europa.eu/observatories/eurwork/industrial-relations-dictionary/european-foundatio n-for-the-improvement-of-living-and-working-conditions-eurofound

Gholamzadeh, S., Sharif, F., \& Rad, F. D. (2011). Sources of occupational stress and coping strategies among nurses who work in Admission and Emergency Departments of Hospitals related to Shiraz University of Medical Sciences. Iranian journal of nursing and midwifery research, 16(1), 41.

Health and Safety Executive, 2012 Health and Safety Executive Annual Statistics Report 2011/12. Retrieved December 12, 2019 from http://www.hse.gov.uk/statistics/overall/hssh1112.pdf

Healy, S., \& Tyrrell, M. (2011). Stress in emergency departments: experiences of nurses and doctors. Emergency nurse, 19(4). https://doi.org/10.7748/en2011.07.19.4.31.c8611

Hooper, C., Craig, J., Janvrin, D. R., Wetsel, M. A., \& Reimels, E. (2010). Compassion satisfaction, burnout, and compassion fatigue among emergency nurses compared with nurses in other selected inpatient specialties. Journal of emergency nursing, 36(5), 420-427. https://doi.org/10.1016/j.jen.2009.11.027

Jones, C. D. (2017). The Effects of Organizational Structures and Management Styles Related to the Burnout and Stress of Psychiatric Nurses (Doctoral dissertation, Northcentral University).

Montero-Marin, J., Prado-Abril, J., Demarzo, M. M. P., Gascon, S., \& García-Campayo, J. (2014). Coping with stress and types of burnout: explanatory power of different coping strategies. PloS one, 9(2), e89090. https://doi.org/10.1371/journal.pone.0089090

Mulcahy, A. (2014). An organization functions only as well as the people who help to run it. Nurses are most often the backbone of what keeps large health care organizations operating functionally and efficiently. Nurses are the body, mind, and spirit of most. Workplace Mental Health Manual for Nurse Managers.

Ross-Adjie, G. M., Leslie, G., \& Gillman, L. (2007). Occupational stress in the ED: What matters to nurses? Australasian Emergency Nursing Journal, 10(3), 117-123. https://doi.org/10.1016/j.aenj.2007.05.005

Salilih, S. Z., \& Abajobir, A. A. (2014). Work-related stress and associated factors among nurses working in public hospitals of Addis Ababa, Ethiopia: A Cross-Sectional Study. Workplace health \& safety, 62(8), 326-332. 
https://doi.org/10.1177/216507991406200803

Sharma, P., Davey, A., Davey, S., Shukla, A., Shrivastava, K., \& Bansal, R. (2014). Occupational stress among staff nurses: Controlling the risk to health. Indian journal of occupational and environmental medicine, 18(2), 52. https://doi.org/10.4103/0019-5278.146890

Spânu, F., Băban, A., Bria, M., \& Dumitrascu, D. L. (2013). What happens to health professionals when the ill patient is the health care system? Understanding the experience of practising medicine in the Romanian socio-cultural context. British journal of health psychology, 18(3), 663-679. https://doi.org/10.1111/bjhp.12010

Wong, D., Leung, S., So, C., \& Lam, D. (2001). Mental health of Chinese nurses in Hong Kong: The roles of nursing stresses and coping strategies. Online Journal of Issues in Nursing, 5(2), 1-22.

\section{Copyrights}

Copyright for this article is retained by the author(s), with first publication rights granted to the journal.

This is an open-access article distributed under the terms and conditions of the Creative Commons Attribution license (http://creativecommons.org/licenses/by/4.0/). 